Check for updates

Cite this: Chem. Sci., 2019, 10, 10275

๑ All publication charges for this article have been paid for by the Royal Society of Chemistry

Received 30th July 2019

Accepted 19th September 2019

DOI: $10.1039 /$ c9sc03779a

rsc.li/chemical-science

\section{Selectivity of tungsten mediated dinitrogen splitting vs. proton reduction $\uparrow$}

\author{
Bastian Schluschaß, ${ }^{a}$ Josh Abbenseth, ${ }^{a}$ Serhiy Demeshko, ${ }^{a}$ Markus Finger, ${ }^{a}$ \\ Alicja Franke, ${ }^{b}$ Christian Herwig, ${ }^{c}$ Christian Würtele, ${ }^{a}$ Ivana Ivanovic-Burmazovic, ${ }^{b}$ \\ Christian Limberg, (D) ${ }^{c}$ Joshua Telser (iD) ${ }^{d}$ and Sven Schneider (iD *a
}

\begin{abstract}
Mo complexes are currently the most active catalysts for nitrogen fixation under ambient conditions. In comparison, tungsten platforms are scarcely examined. For active catalysts, the control of $\mathrm{N}_{2}$ vs. proton reduction selectivities remains a difficult task. We here present $\mathrm{N}_{2}$ splitting using a tungsten pincer platform, which has been proposed as the key reaction for catalytic nitrogen fixation. Starting from [WCl $(\mathrm{PNP})]$ (PNP $\left.=\mathrm{N}\left(\mathrm{CH}_{2} \mathrm{CH}_{2} \mathrm{PtBu}\right)_{2}\right)$, the activation of $\mathrm{N}_{2}$ enabled the isolation of the dinitrogen bridged redox series $\left[\left(\mathrm{N}_{2}\right)\{\mathrm{WCl}(\mathrm{PNP})\}_{2}\right]^{0 /+/ 2+}$. Protonation of the neutral complex results either in the formation of a nitride [W(N)Cl(HPNP)] ${ }^{+}$or $\mathrm{H}_{2}$ evolution and oxidation of the $\mathrm{W}_{2} \mathrm{~N}_{2}$ core, respectively, depending on the acid and reaction conditions. Examination of the nitrogen splitting vs. proton reduction selectivity emphasizes the role of hydrogen bonding of the conjugate base with the protonated intermediates and provides guidelines for nitrogen fixation.
\end{abstract}

\section{Introduction}

Homogeneous $\mathrm{N}_{2}$ fixation under ambient conditions has made remarkable progress over the past 15 years. ${ }^{1}$ Nishibayashi and co-workers recently obtained over 4000 equiv. of $\mathrm{NH}_{3}$ with the proton coupled electron transfer (PCET) reagent $\mathrm{H}_{2} \mathrm{O} / \mathrm{SmI}_{2}$ as $\mathrm{H}^{+} / \mathrm{e}^{-}$sources and a molecular Mo pincer catalyst. ${ }^{2}$ Accordingly, nitrogen reduction (NR) via electrochemically or light-driven PCET with related systems has attracted a lot of attention., ${ }^{3,4}$ Lindley et al. estimated a suitable overpotential window of 1$1.5 \mathrm{~V}$ for selective NR (in MeCN) prior to competing hydrogen reduction (HR) at a glassy carbon cathode. ${ }^{5}$ However, besides the thermochemical framework, mechanistic models that account for NR vs. HR selectivities of molecular catalysts are generally poorly developed.

Several $\mathbf{M}\left(\mathrm{N}_{x} \mathrm{H}_{y}\right)$ intermediates relevant to $\mathrm{N}_{2}$ fixation (Scheme 1) exhibit low $\mathrm{N}-\mathrm{H}$ bond dissociation free energies (BDFEs) below that of free $\mathrm{H}_{2}\left(\mathrm{BDFE}\left(\mathrm{H}_{2}\right.\right.$, gas $\left.)=97.2 \mathrm{kcal} \mathrm{mol}^{-1}\right)$

${ }^{a}$ Georg-August-Universität, Institut für Anorganische Chemie, Tammannstrasse 4, 37077 Göttingen, Germany. E-mail: sven.schneider@chemie.uni-goettingen.de

${ }^{b}$ Lehrstuhl für Bioanorganische Chemie, Department Chemie und Pharmazie, Friedrich-Alexander-Universität Erlangen, Egerlandstrasse 3, 91058 Erlangen, Germany

'Institut für Chemie, Humboldt Universität zu Berlin, Brook-Taylor-Strasse 2, 12489 Berlin, Germany

${ }^{d}$ Department of Biological, Physical and Health Sciences, Roosevelt University, $430 \mathrm{~S}$. Michigan Avenue, Chicago, Illinois 60605, USA

$\dagger$ Electronic supplementary information (ESI) available. CCDC 1943888-1943892. For ESI and crystallographic data in CIF or other electronic format see DOI: $10.1039 / \mathrm{c} 9 \mathrm{sc} 03779 \mathrm{a}$ as possible branching points into HR. ${ }^{6,7}$ Computational evaluation of NR vs. HR selectivities for a series of Fe catalysts pointed at bimolecular $\mathrm{H}_{2}$ loss from species with low $\mathrm{N}-\mathrm{H}$ BDFEs. ${ }^{8,9}$ Attempts to stabilize such $\mathrm{Fe}\left(\mathrm{N}_{x} \mathrm{H}_{y}\right)$ species by hydrogen bonding with pendant bases so far resulted in shutdown of catalysis. ${ }^{10}$ But, in fact, such secondary interactions might also be relevant for Nishibayashi's catalyst as indicated by selectivities obtained with 2,6-lutidinium acids $\left([\mathrm{LutH}]^{+}[\mathrm{X}]^{-}\right)$as the proton source. These strongly depend on the $\mathrm{X}^{-}$counter anion: $\mathrm{NH}_{3} / \mathrm{H}_{2}\left(\mathrm{X}^{-}\right)=7.0\left(\mathrm{Cl}^{-}\right), 0.9\left(\mathrm{OTf}^{-}\right)$, and $0.14\left(\mathrm{BAr}_{4}{ }^{-}\right) \cdot{ }^{11}$

In this contribution, we address the role of hydrogen bonding for the selectivity of proton induced $\mathrm{N}_{2}$ splitting into molecular nitrides $v s$. proton reduction. $\mathrm{N}_{2}$ splitting has evolved as an entry into $\mathrm{N}_{2}$ functionalization for a wide variety of metals ${ }^{12}$ and was proposed as the key step in $\mathrm{N}_{2}$ fixation with Mo pincer catalysts. ${ }^{2,13}$ Cleavage of Cummins' seminal complex 1 (Fig. 1) was attributed to the $\left\{\pi_{1}{ }^{2} \pi_{2}{ }^{2} \pi_{3}{ }^{2} \pi_{4}{ }^{2} \pi_{5}{ }^{1} \pi_{6}{ }^{1}\right\}$ configuration of the $\mathrm{Mo}_{2} \mathrm{~N}_{2}$-core, which enables population of

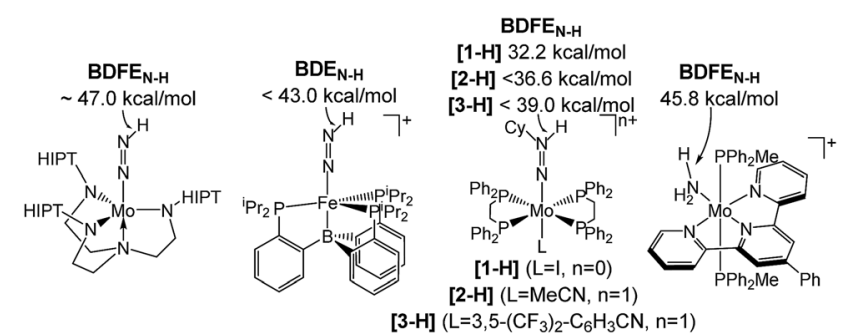

Scheme 1 Transition metal species relevant to $\mathrm{N}_{2}$ fixation with a low BDFE $_{\mathrm{N}-\mathrm{H} \cdot}{ }^{7}$ 


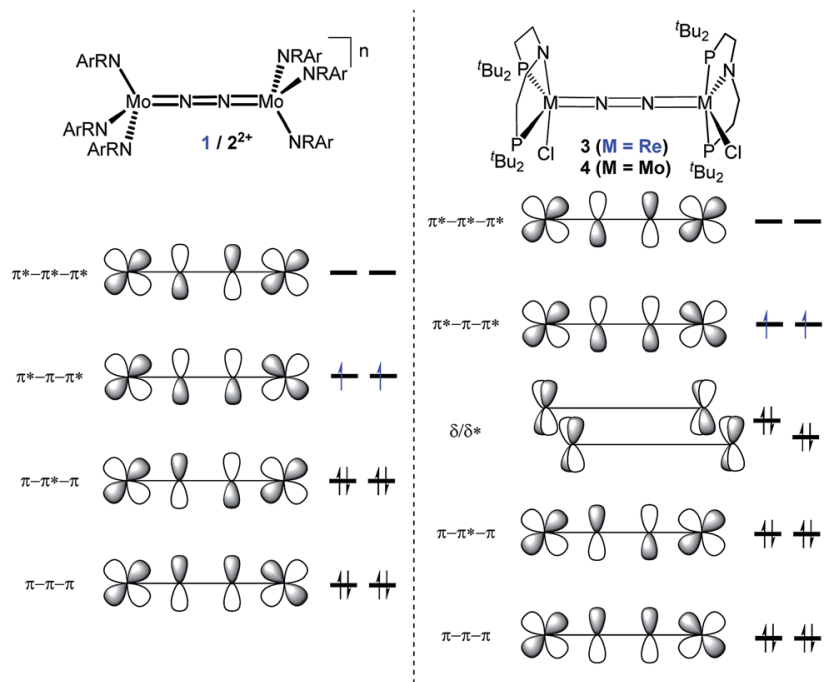

Fig. 1 Qualitative molecular orbital schemes for $1,2^{2+}, 3$ and 4 , illustrating the isolobal relationship of $1\left\{\pi^{10}\right\} / 3\left\{\pi^{10} \delta^{4}\right\}$ and $2^{2+}\left\{\pi^{8}\right\} / 4$ $\left\{\pi^{8} \delta^{4}\right\}$, respectively.

a destabilizing $\sigma$-antibonding molecular orbital (MO) in the transition state. ${ }^{\mathbf{1 4 , 1 5}}$ In contrast, the $\left\{\pi^{8}\right\}$ oxidation product $2^{2+}$ exhibits strong $\mathrm{N}_{2}$ activation (Table 1) but lacks two electrons to form stable $\mathrm{Mo}^{\mathrm{VI}}\left(\mathrm{N}^{3-}\right)$ nitrides. ${ }^{16}$

Similar electronic structure considerations can be applied to metal pincer platforms developed by our group. For example, the square-pyramidally coordinated dinuclear Re complex $\left[\left(\mathrm{N}_{2}\right)\right.$ $\left.\{\operatorname{ReCl}(\mathrm{PNP})\}_{2}\right]\left(3, \mathrm{PNP}=\mathrm{N}\left(\mathrm{CH}_{2} \mathrm{CH}_{2} \mathrm{P} t \mathrm{Bu}_{2}\right)_{2}\right)$ also splits into nitrides at r.t. and exhibits a $\left\{\pi^{10} \delta^{4}\right\}$ configuration that is isolobal with 1 (Fig. 1). ${ }^{17,18}$ In contrast, the $\left\{\pi^{8} \delta^{4}\right\}$ complex $\left[\left(\mathrm{N}_{2}\right)\right.$ $\left.\{\mathrm{MoCl}(\mathrm{PNP})\}_{2}\right]$ (4) features stronger $\mathrm{N}_{2}$-activation comparable to $2^{2+}$ (Table 1), but is thermally stable. ${ }^{19}$ Unexpectedly, splitting of 4 at r.t. was obtained upon protonation of the pincer backbone (Scheme 2), which was rationalized by a protonation induced low-spin $\left\{\pi^{8} \delta^{4}\right\}$ to high-spin $\left\{\pi^{10} \delta^{2}\right\}$ transition that facilitates electron transfer to $\mathrm{N}_{2}$.

Given the impressive $\mathrm{N}_{2}$ fixation rates with Mo pincer catalysts which possibly proceed via $\mathrm{N}_{2}$ splitting;, ${ }^{2,13} \mathrm{~W}$ nitride

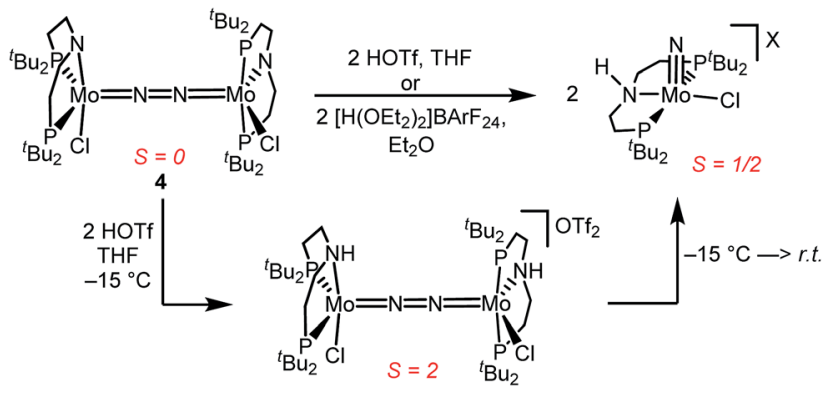

Scheme 2 Dinitrogen splitting coupled to pincer protonation.

formation from $\mathrm{N}_{2}$ is surprisingly rare. ${ }^{20}$ We here report tungsten mediated $\mathrm{N}_{2}$ splitting that competes with proton reduction upon protonation of a $\left\{\mathrm{W}_{2} \mathrm{~N}_{2}\right\}$ pincer complex. Our results provide evidence for the significance of hydrogen bonding for the reaction selectivity.

\section{Results and discussion}

\section{Synthesis of the $\left[\left(\mathrm{N}_{2}\right)\{\mathrm{WCl}(\mathrm{PNP})\}_{2}\right]^{n+}(n=0-2)$ redox series}

The reaction of $\mathrm{WCl}_{4}$ with ${ }^{\mathrm{H}} \mathrm{PNP}$ in the presence of $\mathrm{NEt}_{3}$ gives the pincer complex $\left[\mathrm{WCl}_{3}(\mathrm{PNP})\right](5)$ in yields of up to $60 \%$. In the absence of a signal in the ${ }^{31} \mathrm{P}\left\{{ }^{1} \mathrm{H}\right\}$ NMR spectrum, the paramagnetically shifted ${ }^{1} \mathrm{H}$ NMR signals and the solution magnetic moment derived by Evans' method $\left(\mu_{\text {eff }}=2.8 \pm 0.1 \mu_{\mathrm{B}}\right)$ are in line with a $\mathrm{d}^{2}$ high-spin $(S=1)$ configuration. The molecular structure obtained by X-ray diffraction closely resembles previously reported compounds $\left[\mathrm{MCl}_{3}(\mathrm{PNP})\right](\mathrm{M}=\mathrm{Re}$ and $\mathrm{Mo}) .{ }^{\mathbf{1 8 a}, \mathbf{1 9}}$

Reduction of 5 with $\mathrm{Na} / \mathrm{Hg}$ (2 equiv.) under $\mathrm{N}_{2}(1 \mathrm{~atm})$ in $\mathrm{THF}$ gives the green, $\mathrm{N}_{2}$-bridged dinuclear complex $\left[\left(\mathrm{N}_{2}\right)\right.$ $\left.\{\mathrm{WCl}(\mathrm{PNP})\}_{2}\right](6)$ in up to $66 \%$ isolated yield (Scheme 3$)$. In the solid state (Fig. 2) 6 is isostructural with the molybdenum analogue 4, regarding the $\mathrm{N}_{2}$ binding mode, the approximate $C_{2}$ symmetry due to mutually twisted $\{\mathrm{WCl}(\mathrm{PNP})\}$-fragments (Cl1W1-W1\#-Cl1\#: $\left.89.59^{\circ} / 92.27^{\circ}\right)$, and the distorted squarepyramidal metal coordination $(\tau=0.35) .{ }^{21}$ The short $\mathrm{W}-\mathrm{N}_{2}$ bond $(1.78(2) / 1.82(4) \AA)$ indicates multiple bonding character. In turn, the $\mathrm{N}-\mathrm{N}$ bond $(1.33(4) / 1.27(8) \AA)$ is at the higher end for

Table 1 Comparison of the spectroscopic and structural features of Cummins' Mo- $\mathrm{N}_{2}-$ dimer redox-series $\left(\mathrm{Ar}=\mathrm{C}_{6} \mathrm{H}_{3}-3,5-\mathrm{Me}_{2}\right)^{16}$ with squarepyramidal pincer complexes ( $\mathrm{M}=\mathrm{Re},{ }^{17} \mathrm{Mo},{ }^{19}$ or $\mathrm{W} ;{ }^{*}$ computed value)
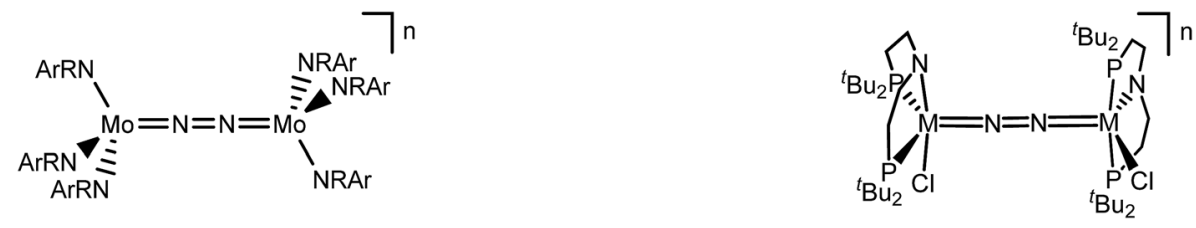

\begin{tabular}{|c|c|c|c|c|c|c|c|c|}
\hline Compound & 1 & - & $2^{2+}$ & $3(\mathrm{M}=\mathrm{Re})$ & $4(\mathrm{M}=\mathrm{Mo})$ & $6(\mathrm{M}=\mathrm{W})$ & $7^{+}(\mathrm{M}=\mathrm{W})$ & $\mathbf{8}^{2+}(\mathrm{M}=\mathrm{W})$ \\
\hline$n$ & 0 & +1 & +2 & 0 & 0 & 0 & +1 & +2 \\
\hline Configuration & $\left\{\pi^{10}\right\}$ & $\left\{\pi^{9}\right\}$ & $\left\{\pi^{8}\right\}$ & $\left\{\pi^{10} \delta^{4}\right\}$ & $\left\{\pi^{8} \delta^{4}\right\}$ & $\left\{\pi^{8} \delta^{4}\right\}$ & $\left\{\pi^{8} \delta^{3}\right\}$ & $\left\{\pi^{8} \delta^{2}\right\}$ \\
\hline$d(\mathrm{NN})[\AA]$ & $1.212(2) / 1.217(2)$ & $1.239(4)$ & $1.265(5)$ & $1.202(10)$ & $1.258(9)$ & $1.33(4) / 1.27(8)$ & $1.277(5)$ & $1.266(12)$ \\
\hline$\nu(\mathrm{NN})\left[\mathrm{cm}^{-1}\right]$ & 1630 & 1503 & 1349 & $1771^{*}$ & 1343 & 1392 & 1414 & 1400 \\
\hline$S$ & 1 & $1 / 2$ & 0 & 1 & 0 & 0 & $1 / 2$ & 1 \\
\hline
\end{tabular}



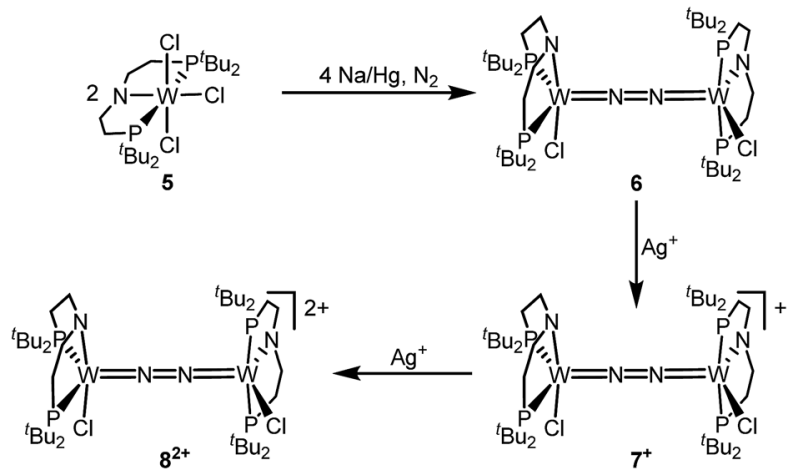

Scheme 3 Preparation of the $\mathrm{N}_{2}$-bridged ditungsten redox series 6 $7^{+}-8^{2+}$.

$\mathrm{N}_{2}$-bridged ditungsten complexes. ${ }^{22}$ The two ${ }^{31} \mathrm{P}\left\{{ }^{1} \mathrm{H}\right\}$ NMR signals $\left(\delta_{\mathrm{P}}=92.9,87.8 \mathrm{ppm}\right)$ with large trans-coupling $\left({ }^{2} J_{\mathrm{PP}}=\right.$ $147 \mathrm{~Hz})$, the singlet ${ }^{15} \mathrm{~N}$ NMR resonance $\left(\delta_{\mathrm{N}}=31.1 \mathrm{ppm}\right)$, and the ${ }^{1} \mathrm{H}$ NMR signature of 6 support a $C_{2}$ symmetric structure also in solution on the NMR timescale.

The $\mathrm{N}_{2}$ stretching vibration of 6 was assigned to the Raman signal at $1392 \mathrm{~cm}^{-1}\left(\lambda_{\text {exc }}=457 \mathrm{~nm}\right.$, THF solution; ${ }^{15} \mathrm{~N}_{2}$ isotopologue: $1347 \mathrm{~cm}^{-1}$ ) supporting strong $\mathrm{N}_{2}$-activation with a formal $\mathrm{N}-\mathrm{N}$ bond order below the double bonding character (trans-diazene: $\nu_{\mathrm{NN}}=1529 \mathrm{~cm}^{-1}$ ). ${ }^{23}$ The closed-shell ground state and degree of $\mathrm{N}_{2}$ activation are in line with the covalent bonding picture described in Fig. 1 . The $\left\{\pi^{8} \delta^{4}\right\}$ configuration of the $\mathrm{W}_{2} \mathrm{~N}_{2}$ core can be rationalized to arise from two low-spin $\mathrm{W}^{\mathrm{II}}$ ions. The twisted conformation enables strong back bonding of each metal ion with one $\pi^{*}$-MO of the $\mathrm{N}_{2}$ bridge, respectively, resulting in net transfer of approximately two electrons as judged from the Raman data. This picture is corroborated by DFT computations, which confirm the $\left\{\pi^{8} \delta^{4}\right\}$ configuration of the $\mathrm{W}_{2} \mathrm{~N}_{2}$ core, analogous to the Mo analogue 4 and Cummins' $2^{2+}$. The blue-shifted $\mathrm{N}_{2}$ stretching vibration of 6 vs. $4\left(\Delta \nu_{\mathrm{NN}}=\right.$ $49 \mathrm{~cm}^{-1}$; Table 1 ) indicates slightly reduced back-bonding by the $5 \mathrm{~d}$ metal.

The redox chemistry of 6 was examined to probe the electronic structure model. Cyclic voltammetry (CV) in THF shows no reduction feature down to $-2.9 \mathrm{~V}$ (vs. $\mathrm{FeCp}_{2}{ }^{+} / \mathrm{FeCp}_{2}$ ). In contrast, two reversible oxidation waves $\left(E_{1}^{\mathrm{o}}=-1.39 \mathrm{~V} ; E_{2}^{\mathrm{o}}=\right.$ $-0.91 \mathrm{~V}$ ) are observed. Both redox events are cathodically shifted by $250 \mathrm{mV}$ with respect to the Mo analogue 4, supporting metal centered oxidation. The oxidation products $\left[\left(\mathrm{N}_{2}\right)\right.$ $\left.\{\mathrm{WCl}(\mathrm{PNP})\}_{2}\right]^{+}\left(7^{+}\right)$and $\left[\left(\mathrm{N}_{2}\right)\{\mathrm{WCl}(\mathrm{PNP})\}_{2}\right]^{2+}\left(\mathbf{8}^{2+}\right)$ could be isolated in yields beyond $80 \%$ upon chemical oxidation of 6 with one and two equivalents of silver salts, respectively (Scheme 3). Stabilization of $\mathbf{8}^{\mathbf{2 +}}$ requires a weakly coordinating anion, which was introduced with $\mathrm{Ag}\left[\mathrm{Al}\left(\mathrm{OC}\left(\mathrm{CF}_{3}\right)_{3}\right)_{4}\right]$ as the oxidant.

In the solid state, $\mathbf{7}^{+}$and $\mathbf{8}^{\mathbf{2 +}}$ resemble the twisted conformation found for 6 (Fig. 2). Distinctly different bond lengths around the two tungsten ions of the mixed-valent complex $7^{+}$ indicate valence localization, which is further supported in solution by the large comproportionation constant $\left(K_{\mathrm{c}} \approx 10^{8}\right)^{24}$ and the X-band EPR spectrum at r.t. The isotropic signal $\left(g_{\mathrm{av}}=\right.$ 1.93) of the low-spin $(S=1 / 2)$ complex exhibits hyperfine interaction (HFI) with only one tungsten $\left(A\left({ }^{183} \mathrm{~W}\right)=220 \mathrm{MHz}\right)$ and two phosphorous nuclei $\left(A\left({ }^{31} \mathrm{P}\right)=56 \mathrm{MHz}\right)$, respectively. HFIs with the $\mathrm{N}_{2}$-bridge are not found and the ${ }^{14} \mathrm{~N}_{2}$ - and ${ }^{15} \mathrm{~N}_{2^{-}}$ isotopologues give identical spectra, further supporting metal centered oxidation. In fact, the degree of $\mathrm{N}_{2}$ activation is almost invariant within the redox series $6 / 7^{+} / 8^{2+}$ as judged from the invariance of the $\mathrm{N}-\mathrm{N}$ stretching vibrations and the $\mathrm{N}-\mathrm{N}$ bond lengths of the $\mathrm{W}_{2} \mathrm{~N}_{2}$ cores (Table 1). Notably, the ${ }^{1} \mathrm{H}$ NMR spectrum of $7^{+}$features four signals assignable to $t \mathrm{Bu}$ groups, in agreement with the averaged $C_{2}$ symmetry and therefore valence delocalization on the slow NMR timescale.

The double oxidation product $\mathbf{8}^{\mathbf{2}}$ exhibits paramagnetically shifted, yet relatively sharp ${ }^{1} \mathrm{H}$ NMR signals. Magnetic characterization by SQUID magnetometry reveals a $\chi_{\mathrm{M}} T$ product of about $0.6 \mathrm{~cm}^{3} \mathrm{~mol}^{-1} \mathrm{~K}^{-1}$ at r.t., which gradually drops to 0 at about $20 \mathrm{~K}$. The data can be fitted to a model with two weakly antiferromagnetically coupled $\left(J=-59 \mathrm{~cm}^{-1}\right)$ low-spin $(S=1 / 2)$ ions. The $g$-value $\left(g_{\mathrm{av}}=1.90\right)$ indicates an orbital contribution in the typical range for $\mathrm{W}^{\mathrm{V}}$ complexes with multiply bound hard ligands, such as oxo or nitrido complexes. ${ }^{25}$

Characterization of the redox series $6 / 7^{+} / 8^{2+}$ supports the electronic structure picture with $\left\{\pi^{8} \delta^{4}\right\} /\left\{\pi^{8} \delta^{3}\right\} /\left\{\pi^{8} \delta^{2}\right\}$ configurations for the $\mathrm{W}_{\mathrm{LS}}^{\mathrm{II}} / \mathrm{W}_{\mathrm{LS}}^{\mathrm{II}}(\mathbf{6}), \mathrm{W}_{\mathrm{LS}}^{\mathrm{II}} / \mathrm{W}_{\mathrm{LS}}^{\mathrm{III}}\left(7^{+}\right)$and $\mathrm{W}_{\mathrm{LS}}^{\mathrm{III}} / \mathrm{W}_{\mathrm{LS}}^{\mathrm{III}}\left(\mathbf{8}^{2+}\right)$ complexes, respectively (Fig. 1 and Table 1 ). The spin orbitals of $7^{+}$and $\mathbf{8}^{2+}$ are orthogonal to the $\mathrm{W}_{2} \mathrm{~N}_{2}$ core resulting in weak
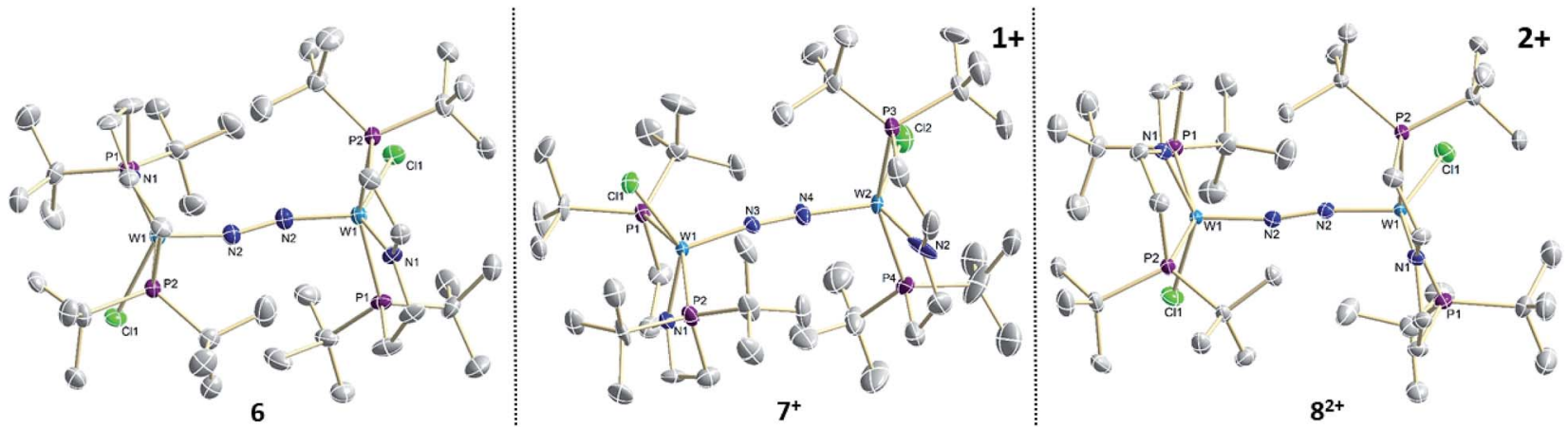

Fig. 2 Molecular structures of $6,7^{+}$and $8^{2+}$ in the crystal obtained by single crystal X-ray diffraction. Hydrogen atoms and anions are omitted for clarity. 
mutual coupling via the $\mathrm{N}_{2}$ bridge $\left(J\left(8^{2+}\right)=-59 \mathrm{~cm}^{-1}\right)$. In consequence, all three complexes of the redox series exhibit strong back bonding to the $\mathrm{N}_{2}$ bridge with only weakly affected degrees of $\mathrm{N}_{2}$ activation. These interpretations are corroborated by DFT (ESI $\dagger$ ). Doublet $\left\{\pi^{8} \delta_{1}{ }^{2} \delta_{2}{ }^{1}\right\}\left(7^{+}\right)$and open-shell singlet $\left\{\pi^{8} \delta_{1}{ }^{1} \delta_{2}{ }^{1}\right\}\left(8^{2+}\right)$ ground states, respectively, were computed with a low lying triplet state for $\mathbf{8}^{\mathbf{2 +}}$ due to weak antiferromagnetic coupling of the metal centered spins $\left(J_{\mathrm{DFT}}=-184 \mathrm{~cm}^{-1}\right)$.

\section{Protonation induced $\mathrm{N}_{2}$ splitting $v s$. proton reduction}

$\mathrm{N}_{2}$ splitting of 6 into the nitride [W(N)Cl(HPNP)]OTf $\left(\mathbf{9}^{\text {OTf }}\right.$, Scheme 4) as the only detectable tungsten species (NMR/EPR spectroscopy, HR-ESI-MS) was achieved upon adding 2 equiv. of triflic acid at $-78{ }^{\circ} \mathrm{C}$ and gradual warming to r.t. Complex $9^{\text {OTf }}$ could be isolated in over $60 \%$ yield and was fully characterized. The tungsten(v) nitride is NMR silent and features an isotropic signal $\left(g_{\mathrm{av}}=1.93\right)$ in the X-band EPR spectrum (THF, r.t.) with HFIs with the tungsten and phosphorous nuclei $\left(A\left({ }^{183} \mathrm{~W}\right)=220 \mathrm{MHz} ; A\left({ }^{31} \mathrm{P}\right)=56 \mathrm{MHz}\right)$. The $\mathrm{W} \equiv \mathrm{N}$ stretching vibration is found in the IR spectrum at $1058 \mathrm{~cm}^{-1}\left({ }^{\mathbf{1 5}} \mathbf{N}-\mathbf{9}^{\text {OTf }}: \Delta \nu\right.$ $=29 \mathrm{~cm}^{-1}$ ). In the solid state (Fig. 3), $\mathbf{9}^{+}$is isostructural with the molybdenum analogue, ${ }^{19}$ featuring square-pyramidally coordinated tungsten with the nitride ligand in the apical site. Hydrogen bonding of the amine proton with the triflate anion is indicated by the short $\mathrm{NH}^{\cdots} \mathrm{O}$ distance $(2.03(3) \AA)$. The $\mathrm{W} \equiv \mathrm{N}$ bond length $(1.679(2) \AA)$ is in the typical range found for the related tungsten nitrides.,17a,26

In contrast to the Mo analogue 4 (Scheme 2), the selectivity of protonation induced $\mathrm{N}_{2}$ splitting strongly varies with the reaction conditions. The addition of HOTf ( 2 equiv.) to 6 at r.t. results in low nitride yields and substantial amounts of the oxidation products $7^{+}$and $\mathbf{8}^{\mathbf{2}}$. Furthermore, 2 equiv. of strong acids with weakly coordinating anions, such as $\left[\mathrm{H}\left(\mathrm{OEt}_{2}\right)_{2}\right]$ $\left[\mathrm{Al}\left(\mathrm{OC}\left(\mathrm{CF}_{3}\right)_{3}\right)_{4}\right]$ and $\left[\mathrm{H}\left(\mathrm{OEt}_{2}\right)_{2}\right] \mathrm{BAr}_{24}^{\mathrm{F}}\left(\mathrm{BAr}_{24}{ }^{-}=\mathrm{B}\left(\mathrm{C}_{6} \mathrm{H}_{3}-3,5-\right.\right.$ $\left.\left.\left(\mathrm{CF}_{3}\right)_{2}\right)_{4}{ }^{-}\right)$, exclusively gave dicationic $8^{2+}$ both at low $\left(-70{ }^{\circ} \mathrm{C}\right)$ and ambient temperatures (Scheme 4). Concomitant $\mathrm{H}_{2}$ evolution was confirmed by gas chromatography. Reaction of 6 at r.t. with 1 equiv. of these and other acids (HOTf, (2,6-lutidinium) OTf, $\left[\mathrm{HNEt}_{3}\right]\left[\mathrm{BAr}_{24}^{\mathrm{F}}\right], \quad\left[\mathrm{H}\left(\mathrm{OEt}_{2}\right)_{2}\right]\left[\mathrm{BAr}^{\mathrm{F}}{ }_{24}\right]$, and $\left[\mathrm{H}\left(\mathrm{OEt}_{2}\right)_{2}\right]$ $\left.\left[\mathrm{Al}\left(\mathrm{OC}\left(\mathrm{CF}_{3}\right)_{3}\right)_{4}\right]\right)$ selectively gives the oxidation product $7^{+}$in all cases.

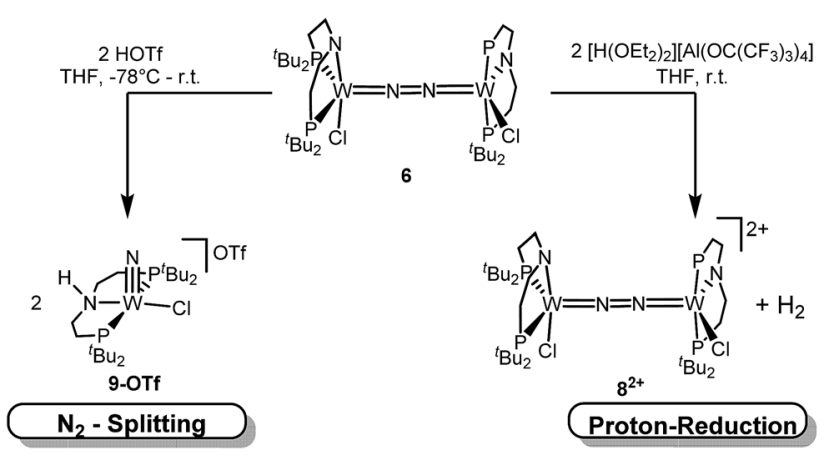

Scheme 4 Protonation of 6 with 2 equiv. of different acids.

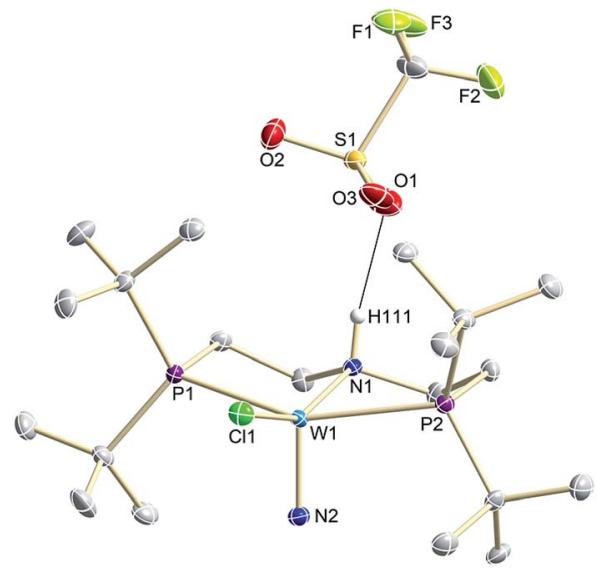

Fig. 3 Molecular structure of $9^{\text {OTf }}$ in the crystal obtained by single crystal X-ray diffraction. Hydrogen atoms are omitted for clarity except H111.

Next, the influence of the acid counteranion on the selectivity was probed. Upon protonation with $\left[\mathrm{HNEt}_{3}\right]\left[\mathrm{BAr}_{24}^{\mathrm{F}}\right]$ (2 equiv.), $7^{+}$was found exclusively (Scheme 5). The second oxidation is hampered by the higher $\mathrm{p} K_{\mathrm{a}}$ of this acid $v s$. HOTf, which prevents protonation of the monocationic product. Importantly, this selectivity changes with [ $\left.\mathrm{HNEt}_{3}\right] \mathrm{OTf}$ ( 2 equiv.): in this case, $7^{+}$is obtained in spectroscopic yields of up to only $30 \%$. In situ HR-ESI-MS examination indicates that nitride $\mathbf{9}^{+}$is formed as the only other product. This observation is reminiscent of acid dependent selectivities reported by Nishibayashi for catalytic nitrogen fixation (see above). ${ }^{11}$ For this reason, $\left[\mathrm{HNEt}_{3}\right]$ Cl (2 equiv.) was also used. Unfortunately, sluggish mixtures of products were obtained, including substantial amounts of trichloride 5. In the next sections, experimental and computational mechanistic examinations with only $\left[\mathrm{HNEt}_{3}\right] \mathrm{X}\left(\mathrm{X}^{-}=\right.$ $\mathrm{BAr}_{24}{ }^{-}$, OTf ${ }^{-}$) are therefore reported.

\section{Mechanistic examinations}

Stoichiometric protonation at low temperatures was carried out to obtain spectroscopic information about intermediates. With 1 equiv. of HOTf at low $T\left(-35^{\circ} \mathrm{C}\right)$, the NMR data are in agreement with pincer protonation to diamagnetic dinuclear

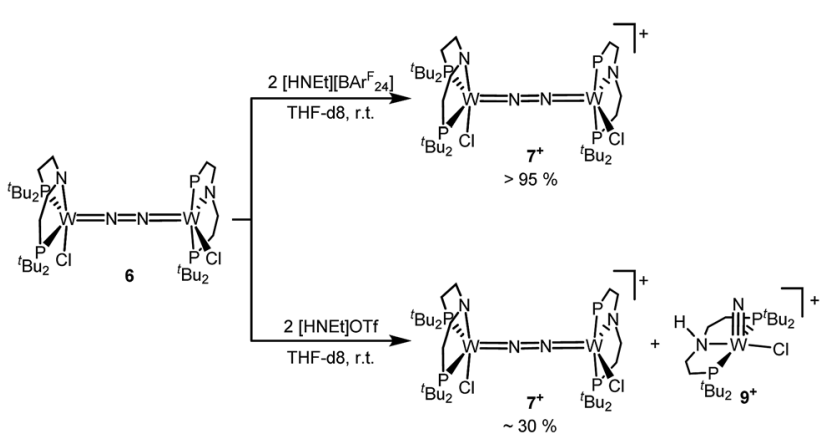

Scheme 5 Anion dependent selectivity for the protonation of 6 with $\left[\mathrm{HNEt}_{3}\right] \mathrm{X}$. 
$C_{1}$-symmetric $\left[(H \mathrm{PNP}) \mathrm{ClW}\left(\mu-\mathrm{N}_{2}\right) \mathrm{WCl}(\mathrm{PNP})\right] \mathrm{OTf}\left(\mathbf{1 0}^{\text {OTf }}\right)$, analogous to the respective Mo system (Scheme 6). ${ }^{19}$

Notably, immediate formation of the oxidation product $7^{+}$ was observed with $\left[\mathrm{H}\left(\mathrm{OEt}_{2}\right)_{2}\right]\left[\mathrm{BAr}_{24}^{\mathrm{F}}\right]$, even at temperatures down to $-75{ }^{\circ} \mathrm{C}$. The enhanced stability of $\mathbf{1 0}^{\text {OTf }}$ suggests an interaction of the immediate protonation product with the triflate anion. Contact-ion pair formation is confirmed by ${ }^{19} \mathrm{~F}$ and ${ }^{1} \mathrm{H}$ DOSY NMR spectroscopy at $-35^{\circ} \mathrm{C}$. The diffusion coefficient of the triflate anion in $10^{\text {OTf }}\left(D=2.29 \times 10^{-6} \mathrm{~cm}^{2} \mathrm{~s}^{-1}\right)$ is in the same range as that of the cation $\left(D=2.18-2.14 \times 10^{-6} \mathrm{~cm}^{2} \mathrm{~s}^{-1}\right)$ and significantly reduced compared to free triflic acid $(D=5.11$ $\times 10^{-6} \mathrm{~cm}^{2} \mathrm{~s}^{-1}$ ). We tentatively attribute the solution ionpairing to hydrogen bonding of the triflate with the pincer $\mathrm{N}-\mathrm{H}$ proton, as found in the solid state for $9^{\mathbf{O T f}}$ (Fig. 3).

Protonation of $\mathbf{6}$ with 2 equiv. of HOTf at low temperatures in THF is associated with a color change from green to yellow. The absence of a signal in the ${ }^{31} \mathrm{P}\left\{{ }^{1} \mathrm{H}\right\}$ NMR spectrum and the broadened and strongly shifted ${ }^{1} \mathrm{H}$ NMR signals indicate the formation of a paramagnetic product. The magnetic moment for the presumable product, $\left[\left(\mathrm{N}_{2}\right)\{\mathrm{WCl}(H \mathrm{PNP})\}_{2}\right]^{\text {OTf2 } 2}\left(\mathbf{1 1}^{\text {OTf2 }}\right)$, was estimated with Evans' method at $-60{ }^{\circ} \mathrm{C}\left(\mu_{\mathrm{eff}}=4.7 \mu_{\mathrm{B}}\right)$, i.e. close to the spin-only value for a quintet ground state $\left(4.9 \mu_{\mathrm{B}}\right)$. Increasing the temperature leads to fading of the color and disappearance of all ${ }^{1} \mathrm{H}$ NMR signals, as expected for selective $\mathrm{N}_{2}$-splitting into the pale, NMR silent nitride product $9^{\text {OTf }}$.

Mechanistic information about proton reduction was obtained from kinetic studies. For this purpose, $\left[\mathrm{HNEt}_{3}\right]\left[\mathrm{BAr}_{24}^{\mathrm{F}}\right]$ was used as the acid, which selectively gives $7^{+}$at r.t. within a convenient timescale even under pseudo first-order conditions. Addition of the acid to 6 in THF leads to an immediate drop of absorbance without significant change of the absorption maxima, suggesting only small changes in the electronic structure. The acid concentration dependence of the absorbance allowed for estimating the equilibrium constant and forward rate of the initial protonation of $6\left(K_{1}=1592 \pm 578\right.$ $\mathrm{M}^{-1}, k_{1}=163 \pm 47 \mathrm{M}^{-1} \mathrm{~s}^{-1}$; Scheme 7 and Fig. S25 and S26 in the ESI $\dagger$ ). This step is followed by a much slower, monoexponential decay, which was monitored over $5 \mathrm{~h}$ (Fig. 4, left). Under pseudo first order conditions in acid $\left(c\left(\mathrm{HNEt}_{3}{ }^{+}\right)_{0} / c(\mathbf{6})_{0}=\right.$ 10-25), the rate constant $\left(k_{\mathrm{obs}(2)}\right)$ linearly depends on the acid concentration (Fig. 4, right), which is in agreement with a slow, irreversible second protonation after the initial, fast preequilibrium $K_{1}$. However, the non-zero intercept indicates the presence of at least one competitive pathway at a low acid

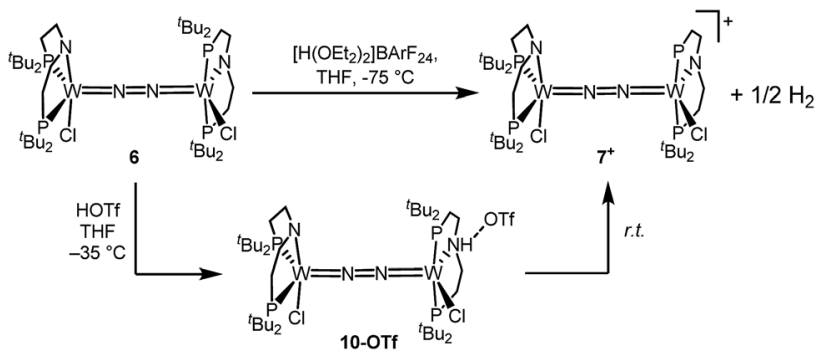

Scheme 6 Oxidation of 6 with 1 equiv. of acid at different temperatures.

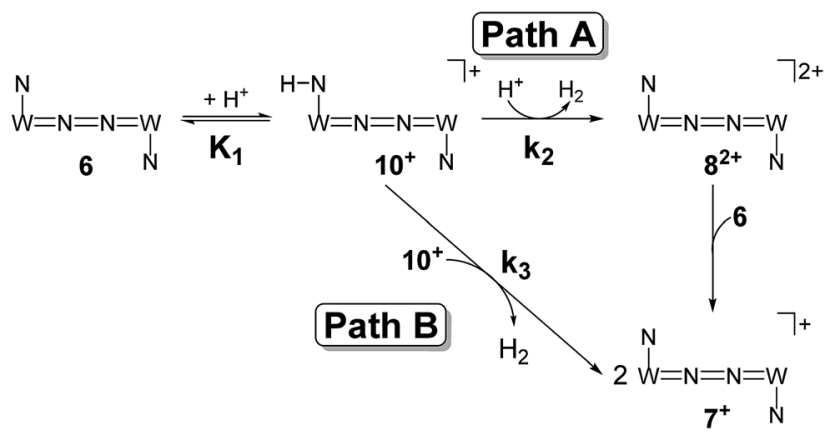

Scheme 7 Proposed mechanistic pathways for proton reduction at high (Path A) and low (Path B) acid concentrations.

concentration. The rate constant $k_{\mathrm{obs}(2)}$ for the formation of $7^{+}$ was therefore expressed as eqn (1) which results from the minimum kinetic model outlined in Scheme 7:

$$
k_{\mathrm{obs}(2)}=\frac{k_{2} K_{1}\left[\mathrm{H}^{+}\right]^{2}}{1+K_{1}\left[\mathrm{H}^{+}\right]}+k_{3 \mathrm{obs}}
$$

The first term accounts for the initial protonation of 6 to give $10^{+}$, followed by irreversible $\mathrm{H}_{2}$ release from acid and $\mathbf{1 0}^{+}$. Rapid, subsequent comproportionation of the resulting $8^{2+}$ with 6 to $2 \times 7^{+}$is in line with the electrochemical results $\left(K_{\mathrm{c}} \approx 10^{8}\right.$, see above). The second term in eqn (1) is ascribed to bimolecular decay of $\mathbf{1 0}^{+}$as an alternative path at low acid concentrations. The rate constant $k_{2}=0.018 \pm 0.001 \mathrm{M}^{-1} \mathrm{~s}^{-1}$ was derived from fitting the experimental data to eqn (1) (with preserved $K_{1}$ ) under pseudo first order conditions in acid (10-25 equiv.). The rate constant $k_{3}=0.4 \mathrm{M}^{-1} \mathrm{~s}^{-1}$ for the bimolecular path at low acid concentrations was obtained from the initial rate of the reaction of 6 and an equimolar amount of $\left[\mathrm{HNEt}_{3}\right]\left[\mathrm{BAr}_{24}^{\mathrm{F}}\right] . \neq$

Kinetic analysis suggests two pathways for $\mathrm{H}_{2}$ formation which both go through the spectroscopically characterized common intermediate $\mathbf{1 0}^{+}$(as 10 ${ }^{\text {OTf }}$ ). Path B (Scheme 7) explains the decay of $\mathbf{1 0}^{+}$even in the absence of the acid and reflects a bimolecular $\mathrm{H}_{2}$ formation route as proposed by Matson and Peters for an iron diazenide $\mathrm{N}_{2}$-fixation intermediate. ${ }^{8}$ However, path $\mathrm{A}$ is predominant with excess acid. Besides these routes for hydrogen evolution, splitting of the $\mathrm{N}_{2}$ bridge is observed in the presence of triflate as the counteranion and is even selective at
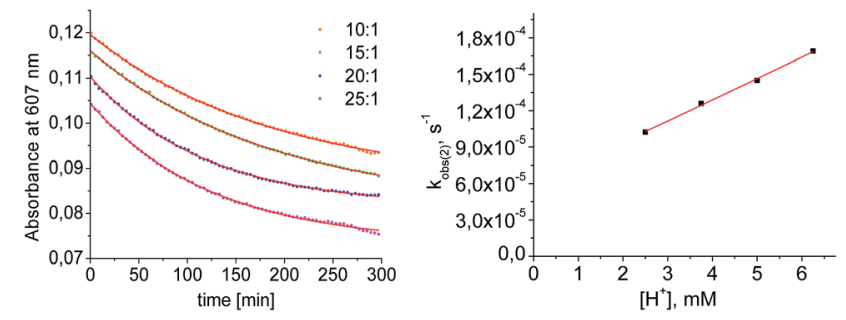

Fig. 4 Left: plot of the absorbance at $607 \mathrm{~nm}$ vs. time for different concentrations of $\left[\mathrm{HNEt}_{3}{ }^{+}\right]$. Results from fitting to the rate law are indicated by red lines. Right: plot of $k_{\mathrm{obs}(2)} \mathrm{vs}$. $\left[\mathrm{HNEt}_{3}{ }^{+}\right.$]. 
lower temperatures. These effects are rationalized computationally in the next section.

\section{Computational examinations}

Protonation with $\left[\mathrm{NEt}_{3} \mathrm{H}\right]\left[\mathrm{BAr}_{24}^{\mathrm{F}}\right]$ was first examined computationally with trimethylammonium as the model acid (Scheme 8). Two different sites, a metal ion and a pincer nitrogen atom, respectively, were considered for the first protonation step. A hydride product $\left[(\mathrm{PNP}) \mathrm{W}(\mathrm{H}) \mathrm{Cl}\left(\mu-\mathrm{N}_{2}\right) \mathrm{WCl}(\mathrm{PNP})\right]^{+}\left(\mathbf{1 2}^{+}\right)$adopts an electronic singlet $(S=0)$ ground state and was found to be the global protonation minimum at $\Delta G_{298 \mathrm{~K}}^{\circ}=-4.7 \mathrm{kcal} \mathrm{mol}^{-1}$ below 6 and $\left[\mathrm{NMe}_{3} \mathrm{H}\right]^{+}$. Hence, the model computation is in excellent agreement with the experimental equilibrium constant $K_{1}$. The computed structure of $\mathbf{1 2}^{+}$features a bridging hydride between the metal ion and a pincer phosphorous atom. A similar structure was previously found experimentally by Schrock and co-workers for the protonation of a PCP molybdenum(Iv) nitride by $\left[\mathrm{NEt}_{3} \mathrm{H}\right]\left[\mathrm{BAr}^{\mathrm{F}}{ }_{24}\right] .^{27}$ All efforts to experimentally verify hydride intermediates like $\mathbf{1 2}^{+}$were unfortunately unsuccessful. However, pincer protonation to $\mathbf{1 0}^{+}$ is only slightly less exergonic $\left(\Delta G_{298 \mathrm{~K}}^{\circ}=-2.9 \mathrm{kcal} \mathrm{mol}^{-1}\right)$. Importantly, this state is further stabilized upon use of $\left[\mathrm{NEt}_{3} \mathrm{H}\right]$ OTf as the acid due to hydrogen bonding of the pincer amine moiety with the triflate anion by $\left(\Delta \Delta G_{298 \mathrm{~K}}^{\circ}=-2.1 \mathrm{kcal} \mathrm{mol}^{-1}\right)$. In contrast, the hydride ligand is not involved in hydrogen bonding, rendering $\mathbf{1 0}^{\text {OTf }}$ $\left(\Delta G_{298 \mathrm{~K}}^{\circ}=-5.0 \mathrm{kcal} \mathrm{mol}^{-1}\right)$ the global minimum of the first protonation in the presence of triflate. Overall, the metal and pincer protonation products $\mathbf{1 2}^{+}$and $\mathbf{1 0}^{+}$(and $\mathbf{1 0}^{\text {OTf }}$ in the presence of triflate) should be in rapid equilibrium under these conditions, which is slightly shifted towards pincer protonation by hydrogen bonding with the counteranion. Notably, hydrogen bonding with the conjugate base $\mathrm{NMe}_{3}$ was not observed, presumably for steric reasons.

Starting from the amine/hydride equilibrium, the second protonation with $\left[\mathrm{NMe}_{3} \mathrm{H}\right]^{+}$can ultimately lead to hydrogen evolution or $\mathrm{N}_{2}$ splitting, respectively. The formation of $\mathrm{H}_{2}$ and dicationic $\mathbf{8}^{\mathbf{2 +}}$, which represents Path A (Scheme 7), was computed to be exergonic by $\left(\Delta G_{298 \mathrm{~K}}^{\circ}=-12.8 \mathrm{kcal} \mathrm{mol}^{-1}\right)$ with respect to 6 . The most reasonable pathway (Scheme 8, right branch) proceeds via hydride protonation of $\mathbf{1 2}^{+}$leading to the dihydrogen intermediate $\left[(\mathrm{PNP}) \mathrm{W}\left(\mathrm{H}_{2}\right) \mathrm{Cl}\left(\mu-\mathrm{N}_{2}\right) \mathrm{WCl}(\mathrm{PNP})\right]^{2+}$ $\left(\mathbf{1 3}^{\mathbf{2 +}}\right)$, which is unstable and readily releases $\mathrm{H}_{2}$ without barriers. While the transition state that leads from $12^{+}$to $\mathbf{1 3}^{2+}$ could not be reliably located due to the flat potential energy profile of protonation, the free energy of $\mathbf{1 3}^{\mathbf{2 +}}$ $\left(\Delta \Delta G_{298 \mathrm{~K}}^{\circ}=+19.7 \mathrm{kcal} \mathrm{mol}^{-1}\right.$ with respect to $\left.12^{+}\right)$was used as an estimate for the kinetic barrier of hydride protonolysis. $\S$ Notably, this value is in excellent agreement with the experimentally derived barrier for Path A $\left(k_{2}=0.018 \mathrm{M}^{-1} \mathrm{~s}^{-1} ; \Delta G_{\mathrm{eff}}^{\ddagger}=\right.$ $19 \mathrm{kcal} \mathrm{mol}^{-1}$ ).

Alternatively, splitting of the dinitrogen bridge (Scheme 8, left branch) was computed to proceed via protonation of the second pincer nitrogen. In the absence of triflate, $\left[\left(\mathrm{N}_{2}\right)\{\mathrm{WCl}(H \mathrm{PNP})\}_{2}\right]^{2+}$ $\left(\mathbf{1 1}^{\mathbf{2 +}}\right)$ was located at $\Delta G_{298 \mathrm{~K}}^{\circ}=+5.0 \mathrm{kcal} \mathrm{mol}^{-1}$ vs. 6 $\left(\Delta G_{298 \mathrm{~K}}^{\circ}=+9.7 \mathrm{kcal} \mathrm{mol}^{-1}\right.$ vs. the global first protonation minimum $\left.12^{+}\right)$adopting an electronic quintet $(S=2)$ ground state in accordance with the experimental findings for $\mathbf{1 1}^{\text {OTf2 }}$. From there, $\mathrm{N}_{2}$ cleavage into the nitrides $\mathbf{9}^{+}$was computed to be strongly exergonic $\left(\Delta G_{298 \mathrm{~K}}^{\circ}=-49.7 \mathrm{kcal} \mathrm{mol}^{-1}\right)$ with a kinetic barrier $\left(\Delta G_{298 \mathrm{~K}}^{+}=21.7 \mathrm{kcal} \mathrm{mol}^{-1}\right)$ that is comparable to the experimentally derived barriers for $\left[\left(\mathrm{N}_{2}\right)\{\operatorname{MoCl}(H \mathrm{PNP})\}_{2}\right]^{2+}$ $\left(\Delta G_{298 \mathrm{~K}}^{\ddagger}=19.5 \mathrm{kcal} \mathrm{mol}^{-1}\right)$ and $\left[\left(\mathrm{N}_{2}\right)\{\operatorname{ReCl}(\mathrm{PNP})\}_{2}\right]\left(\Delta G_{298 \mathrm{~K}}^{\ddagger}=\right.$ $\left.19.8 \mathrm{kcal} \mathrm{mol}^{-1}\right)$, respectively. For the tungsten system, this gives

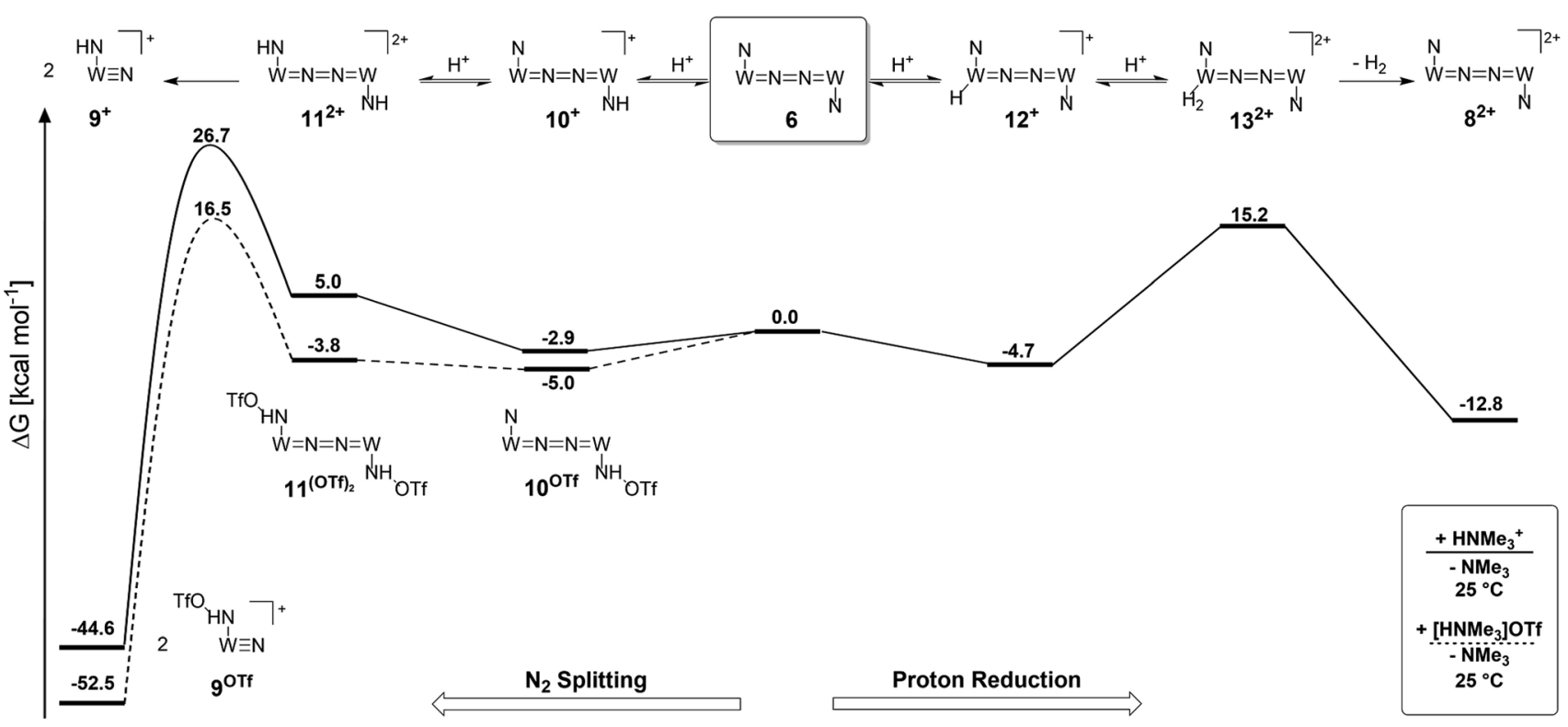

Scheme 8 Computed energy profile for protonation induced $\mathrm{N}_{2}$ splitting (left branch) and hydrogen evolution via Path A (right branch) via double protonation of the dinitrogen complex 6 at room temperature in the absence (solid line) and presence (dashed line) of triflate as the counteranion. 
rise to an overall effective barrier for protonation induced $\mathrm{N}_{2}$ splitting from the most stable monoprotonation intermediate, hydride $\mathbf{1 2}^{+}$, of $\Delta G_{\mathrm{eff}}^{\ddagger}=31.4 \mathrm{kcal} \mathrm{mol}^{-1}$. This value is considerably higher than the estimate for the hydrogen evolution pathway $\left(\Delta \Delta G_{\text {eff }}^{ \pm}=+11.5 \mathrm{kcal} \mathrm{mol}^{-1}\right)$, which is in line with selective proton reduction with $\left[\mathrm{NEt}_{3} \mathrm{H}\right]\left[\mathrm{BAr}_{24}^{\mathrm{F}}\right]$ as the acid.

Importantly, the relative energetics of these two reaction channels are perturbed in the presence of triflate as the counteranion. As was found for the first pincer protonation (see above), triflate hydrogen bonding stabilizes the pincer diprotonation product $\mathbf{1 1}^{\text {OTf2 }}$ by $-8.8 \mathrm{kcal} \mathrm{mol}^{-1}$. Consequently, the estimated effective barrier for hydrogen evolution $\left(\Delta G_{298 \mathrm{~K}}^{\ddagger}=\right.$ $20.2 \mathrm{kcal} \mathrm{mol}^{-1} v s$. the global first protonation minimum in the presence of triflate $\mathbf{1 0}^{\mathbf{\text { OTf}}}$ ) is slightly raised. On the other hand, the $\mathrm{N}_{2}$ splitting pathway $\left(\Delta G_{298 \mathrm{~K}}^{*}=21.5 \mathrm{kcal} \mathrm{mol}^{-1} v s . \mathbf{1 0}^{\mathbf{O T f}}\right)$ is almost isoenergetic, in full agreement with the experimental findings. The triflate induced effect on selectivity is therefore attributed to Curtin-Hammett controlled reactivity wherein $\mathrm{N}-\mathrm{H}$ hydrogen bonding to the counteranion modifies the energetics of the protonation pre-equilibria.

A similar picture evolves for the reaction with triflic acid (see the ESI, Scheme S1†). However, the potential energy of protonation is augmented by the higher driving force with the stronger acid $\left(\mathrm{p} K_{\mathrm{a}}^{\mathrm{THF}}\left(\mathrm{Et}_{3} \mathrm{NH}^{+}\right)-\mathrm{p} K_{\mathrm{a}}^{\mathrm{THF}}(\mathrm{HOTf})=4.7\right){ }^{28}$ This affects the selectivity as the effective barrier for the $\mathrm{N}_{2}$ splitting branch versus hydrogen evolution is close in energy. Furthermore, all rate determining states are below the starting point 6 . In consequence, under these conditions (HOTf as the acid at r.t.), Curtin-Hammett conditions do not apply resulting in the experimentally observed low selectivity.

Reduction of the temperature to $-80{ }^{\circ} \mathrm{C}$ further perturbs the relative energetics of the two reaction pathways with HOTf. The computed amine $\left(\Delta G_{193 \mathrm{~K}}^{\circ}\left(\mathbf{1 0}^{\text {OTf }}\right)=15.1 \mathrm{kcal} \mathrm{mol}^{-1}\right) \quad v s$. hydride $\left(\Delta G_{193 \mathrm{~K}}^{\circ}\left(\mathbf{1 2}^{+}\right)=-10.3 \mathrm{kcal} \mathrm{mol}^{-1}\right)$ equilibrium is even more shifted towards the amine due to the lower entropic penalty for hydrogen bonding at low $T$. The negligible population of the hydride tautomer is in agreement with the exclusive experimental observation of $10^{\text {OTf }}$ and $11^{\text {OTf2 }}$ upon single and double protonation with HOTf at $-80^{\circ} \mathrm{C}$. From $11^{\text {OTf2 }}$, the dihydrogen complex $\mathbf{1 3}^{2+}\left(\Delta G_{193 \mathrm{~K}}^{\circ}\left(\mathbf{1 3}^{\mathbf{2 +}}\right)-\Delta G_{193 \mathrm{~K}}^{\circ}\left(\mathbf{1 1}^{\mathrm{OTf} 2}\right)=+27.7 \mathrm{kcal} \mathrm{mol}^{-1}\right)$ is much higher in free energy than the barrier for $\mathrm{N}_{2}$ splitting $\left(\Delta G_{193 \mathrm{~K}}^{\star}=19.9 \mathrm{kcal} \mathrm{mol}^{-1}\right)$, in line with selective $\mathrm{N}_{2}$ splitting upon double protonation with HOTf at $-80{ }^{\circ} \mathrm{C}$ and slow warming.

\section{Concluding remarks}

In summary, an anion effect on the selectivity of proton induced dinitrogen splitting (NR) vs. hydrogen evolution (HR) at the $\mathrm{N}_{2}$ bridged ditungsten complex 6 was demonstrated and rationalized. Our spectroscopic, kinetic and computational studies suggest some guidelines to improve NR over HR yields:

(a) Nitrogen vs. metal protonation offers separate reaction channels with a proposed hydride isomer leading to hydrogen evolution analogous to the highly active Mo-oxo polypyridyl HR catalysts. $^{29}$ The tautomerisation equilibrium can be offset by hydrogen bonding with protic $\mathrm{N}-\mathrm{H}$ hydrogen atoms favoring the use of an acid $[\mathrm{BH}]^{+} \mathrm{X}^{-}$where the anion $\mathrm{X}^{-}$is prone to form H-bonds for high NR selectivity.

(b) Protonation under Curtin-Hammett control with weak acids can become irreversible with strong acids. Hence, the $\mathrm{p} K_{\mathrm{a}}$ of the acid can have a decisive kinetic effect on the selectivity.

(c) Lower temperatures favour hydrogen bonding interactions due to the reduced entropic penalty as a strategy for increased NR yields.

Besides the immediate application to the current system, these findings might be considered as a model reaction for nitrogen fixation schemes. The studies of Peters and of Nishibayashi have emphasized the importance of proton coupled electron transfer for $\mathrm{N}_{2}$ fixation under ambient conditions. Our kinetic model might therefore offer some general strategies regarding the choice of acid to improve NR selectivities with respect to unproductive proton reduction.

\section{Conflicts of interest}

There are no conflicts to declare.

\section{Acknowledgements}

This work was funded by the European Research Council (ERC Grant Agreement 646747). The authors thank Dr C. Volkmann for X-ray diffraction analysis of compounds 5 and 6, Dr S. Dechert for recording Raman spectra of 6 and $7^{+}$and Dr C. Stückl for EPR measurements of $7^{+}$and $\mathbf{9}^{+}$.

\section{Notes and references}

$\ddagger$ An alternative pathway via reduction of $10^{+}$with $\mathbf{6}$ is less likely based on the derived rate constant $\left(k_{3}^{\prime}=0.12 M^{-1} s^{-1}\right)$, which is considerably smaller than $k_{3}$. $\S$ A transition state for the direct protonation of $\mathbf{1 2}^{+}$with $\mathrm{HNMe}_{3}{ }^{+}$at the hydride ligand was located at $25.4 \mathrm{kcal} \mathrm{mol}^{-1}$ above 6 and two equivalents of $\left[\mathrm{HNMe}_{3}\right]^{+}$. However, this activation free energy is considerably higher than the experimentally determined value $\left(\Delta G_{\text {eff }}^{\ddagger}=19 \mathrm{kcal} \mathrm{mol}^{-1}\right)$. It is not clear if this deviation can be attributed to the computational truncation of the acid or to a lower competing pathway. We therefore prefer to use the experimental value for the discussion of the selectivity. See also the ESI for further discussion. $\dagger$

1 (a) R. Schrock, Angew. Chem., Int. Ed., 2008, 47, 5512-5522; (b) J. S. Anderson, J. Rittle and J. C. Peters, Nature, 2013, 501, 84-87; (c) K. C. MacLeod and P. Holland, Nat. Chem., 2013, 5, 559-565; (d) H. Tanaka, Y. Nishibayashi and K. Yoshizawa, Acc. Chem. Res., 2016, 49, 987-995.

2 Y. Ashida, K. Arashiba, K. Nakajima and Y. Nishibayashi, Nature, 2019, 568, 536-540.

3 (a) N. Thompson, M. Green and J. Peters, J. Am. Chem. Soc., 2017, 139, 15312-15315; (b) M. J. Chalkley, T. J. Del Castillo, B. D. Matson and J. Peters, J. Am. Chem. Soc., 2018, 140, 6122-6129.

4 (a) D. Wang, F. Loose, P. J. Chirik and R. R. Knowles, J. Am. Chem. Soc., 2019, 141, 4795-4799; (b) F. Loose, D. Wang, L. Tian, G. D. Scholes, R. R. Knowles and P. J. Chirik, Chem. Commun., 2019, 55, 5595-5598.

5 B. M. Lindley, A. M. Appel, K. Krogh-Jespersen, J. M. Mayer and A. J. M. Miller, ACS Energy Lett., 2016, 1, 698-704. 
6 J. J. Warren, T. A. Tronic and J. M. Mayer, Chem. Rev., 2010, 110, 6961-7001.

7 (a) D. J. Yandulov and R. R. Schrock, Inorg. Chem., 2005, 44, 1103-1117; (b) J. Rittle and J. C. Peters, J. Am. Chem. Soc., 2017, 139, 3161-3170; (c) M. J. Bezdek and P. Chirik, Dalton Trans., 2016, 45, 15922; (d) M. J. Bezdek, S. Guo and P. J. Chirik, Science, 2016, 354, 730-733.

8 B. D. Matson and J. C. Peters, ACS Catal., 2018, 8, 1448-1455.

9 T. J. Del Castillo, N. B. Thompson and J. C. Peters, J. Am. Chem. Soc., 2016, 138, 5341-5350.

10 S. E. Creutz and J. C. Peters, Chem. Sci., 2017, 8, 2321-2328.

11 K. Arashiba, Y. Miyake and Y. Nishibayashi, Nat. Chem., 2011, 3, 120-125.

12 I. Klopsch, E. Y. Yuzik-Klimova and S. Schneider, Top. Organomet. Chem., 2017, 60, 71.

13 K. Arashiba, A. Eizawa, H. Tanaka, K. Nakajima, K. Yoshizawa and Y. Nishibayashi, Bull. Chem. Soc. Jpn., 2017, 90, 1111.

14 C. E. Laplaza and C. C. Cummins, Science, 1995, 268, 861.

15 C. E. Laplaza, M. J. A. Johnson, J. C. Peters, A. L. Odom, E. Kim, C. C. Cummins, G. N. George and I. J. Pickering, J. Am. Chem. Soc., 1996, 118, 8623-8638.

16 J. J. Curley, T. R. Cook, S. Y. Reece, P. Müller and C. C. Cummins, J. Am. Chem. Soc., 2008, 130, 9394-9405.

17 (a) I. Klopsch, M. Finger, C. Würtele, B. Milde, D. B. Werz and S. Schneider, J. Am. Chem. Soc., 2014, 136, 6881; (b) B. M. Lindley, R. S. van Alten, M. Finger, F. Schendzielorz, C. Würtele, A. J. M. Miller, I. Siewert and S. Schneider, J. Am. Chem. Soc., 2018, 140, 7922.

18 (a) I. Klopsch, M. Kinauer, M. Finger, C. Würtele and S. Schneider, Angew. Chem., Int. Ed., 2016, 55, 4786; (b) I. Klopsch, F. Schendzielorz, C. Volkmann, C. Würtele and S. Schneider, Z. Anorg. Allg. Chem., 2018, 644, 916; (c) F. Schendzielorz, M. Finger, J. Abbenseth, C. Würtele, V. Krewald and S. Schneider, Angew. Chem., Int. Ed., 2019, 58, 830 .

19 G. Silantyev, M. Förster, B. Schluschaß, J. Abbenseth, C. Würtele, C. Volkmann, M. C. Holthausen and S. Schneider, Angew. Chem., Int. Ed., 2017, 56, 5872.

20 (a) A. J. Keane, W. S. Farrell, B. L. Yonke, P. Y. Zavalij and L. R. Sita, Angew. Chem., Int. Ed., 2015, 54, 10220-10224; (b) L. M. Duman, W. S. Farrell, P. Y. Zavalij and L. R. Sita, J. Am. Chem. Soc., 2016, 138, 14856-14859.

21 A. W. Addison, N. T. Rao, J. Reedijk, J. van Rijn and G. C. Verschoor, J. Chem. Soc., Dalton Trans., 1984, 1349.

22 (a) M. R. Churchill, Y. J. Li, K. H. Theopold and R. R. Schrock, Inorg. Chem., 1984, 23, 4472-4476; (b) R. C. Murray and R. R. Schrock, J. Am. Chem. Soc., 1985, 107, 4557-4558; (c) M. R. Churchill and Y. J. Li, J. Organomet. Chem., 1986, 301, 49-59; (d) M. Scheer, J. Müller, M. Schiffer, G. Baum and R. Winter, Chem. - Eur. J., 2000, 6, 1252-1257; (e) P. P. Fontaine, B. L. Yonke, P. Y. Zavalij and L. R. Sita, J. Am. Chem. Soc., 2010, 132, 12273-12285.

23 (a) J. R. Durig, M. G. Griffin and R. W. MacNamee, J. Raman Spectrosc., 1975, 3, 133; (b) N. C. Craig and I. W. Levin, J. Chem. Phys., 1979, 71, 400.

24 For critical discussion of $K_{\mathrm{c}}$ as a descriptor of valence tautomerism see: W. Kaim and B. Sarkar, Coord. Chem. Rev., 2007, 251, 584-594.

25 Representative examples: (a) W. Levason, C. A. McAuliffe and F. P. McCullough Jr., Inorg. Chem., 1977, 16, 2911-2916; (b) K. Frick, S. Verma, J. Sundermeyer and M. Hanack, Eur. J. Inorg. Chem., 2000, 1025-1030; (c) S. Sproules, A. A. Eagle, M. K. Taylor, R. W. Gable, J. M. White and C. G. Young, Inorg. Chem., 2011, 50, 4503-4515.

26 (a) K. Dehnicke and J. Strähle, Angew. Chem., Int. Ed., 1981, 20, 413-426; (b) M. H. Chisholm, D. M. Hoffman and J. C. Huffman, Inorg. Chem., 1983, 22, 2903-2906; (c) C. R. Clough, J. B. Greco, J. S. Figueroa, P. L. Diaconescu, W. M. Davis and C. C. Cummins, J. Am. Chem. Soc., 2004, 126, 7742-7743; (d) K. R. McClain, C. O'Donohue, A. Koley, R. O. Bonsu, K. A. Abboud, J. C. Revelli, T. J. Anderson and L. McElwee-White, J. Am. Chem. Soc., 2014, 136, 1650-1662; (e) A. Lackner and A. Fürstner, Angew. Chem., Int. Ed., 2015, 54, 12814-12818.

27 T. J. Hebden, R. R. Schrock, M. K. Takase and P. Müller, Chem. Commun., 2012, 48, 1851-1853.

28 A. Kütt, S. Selberg, I. Kaljurand, S. Tshepelevitsh, A. Heering, A. Darnell, K. Kaupmees, M. Piirsalu and I. Leito, Tetrahedron Lett., 2018, 59, 3738-3748.

29 D. Z. Zee, T. Chantarojsiri, J. R. Long and C. J. Chang, Acc. Chem. Res., 2015, 48, 2017-2036. 